\title{
"Diz-me onde moras e te direi quem és": um estudo de hierarquia habitacional na Cidade Alta - Rio de Janeiro
}

\author{
"Tell me where you live and I'll say who you are": a study of \\ dwelling hierarchy in Cidade Alta - Rio de Janeiro
}

Wellington da Silva Conceição ${ }^{1}$

\begin{abstract}
Resumo
O presente artigo apresenta um estudo socioantropológico sobre hierarquia, tendo como foco distintas realidades habitacionais na cidade do Rio de Janeiro. Após apresentar uma breve história da hierarquia habitacional e seus principais tipos de classificação, o texto traz resultados de um trabalho de campo, realizado no bairro Cidade Alta (Rio de Janeiro-RJ), como um estudo de caso que representa bem as relações sociais que se dão a partir de concepções hierárquicas sobre diferentes realidades habitacionais. As obras Homo hierarquicus: o sistema de castas e as suas implicações, de Louis Dumont, e A casa \& A Rua, de Roberto DaMatta, servem como pano de fundo e inspiração para análise.
\end{abstract}

Palavras-chave: Hierarquia. Favela. Conjunto habitacional.

\begin{abstract}
:
This article intends to show an anthropological/sociological study about hierarchy, bringing into focus different dwelling realities in Rio de Janeiro City. After showing a brief background about dwelling hierarchy history in the city and its main kinds of classification, the work presents results of a field study in Cidade Alta (Rio de Janeiro - RJ), as a case that summarizes the social relations occurring from hierarchical conceptions about different dwelling realities. The works Homo hierarquicus: 0 sistema de castas e as suas implicações, by Louis Dumont, and A casa \& A Rua, by Roberto DaMatta, play here the role of background and inspiration for this analysis.
\end{abstract}

Keywords: Hierarchy. Slum. Dwelling complex.

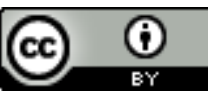

Esta obra foi licenciada com uma Licença Creative Commons - Atribuição 3.0 Não Adaptada.

1 Doutorando em Ciências Sociais (PPCIS-UERJ). Pesquisador Associado do Laboratório de Etnografia Metropolitano/LeMetro/IFCS-UFRJ. E-mail: welsc29@yahoo.fr

Cad. de Pesq. Interdisc. em Ci-s. Hum-s. Florianópolis, Santa Catarina, Brasil, ISSN 1984-8951 v.14, n.105, p.120-138, ago/dez 2013 


\section{Introdução}

Dumont, em sua obra Homo hierarchicus: o sistema de casta e as suas implicações, trazia resultados da sua pesquisa de campo na Índia, sociedade assumidamente hierárquica, e também as observações e representações que a sociedade ocidental, que se declarava igualitária, construía sobre o sistema de castas. Entre as conclusões apresentadas por Dumont, ressalto sua brilhante descoberta de que, nas sociedades hierárquicas, existem características que se baseiam na igualdade e no individualismo, e nas sociedades igualitárias e individualistas, por mais que se rejeitem práticas como o sistema de castas, podemos encontrar atitudes hierárquicas. E mais, muitas vezes o discurso igualitário pode ser baseado em um discurso hierárquico, instituindo, por exemplo, diferenças de classe e de gênero.

Essas observações, feitas por Dumont, tiveram como referência a Índia e a Europa. Porém, nossa realidade brasileira, declaradamente igualitária, como todo o ocidente, mas observada como híbrida por DaMatta (1997a, p. 169-259), apresenta diversas situações que mostram a forte presença da hierarquia nas nossas estruturas sociais. As conclusões de Dumont e de DaMatta foram importantes para entender aspectos presentes em meu trabalho de campo, em que identificava hierarquias com grande valor simbólico na formação das representações e das identidades do grupo social que pesquisava. Neste texto, apresento resultados de uma pesquisa sobre a hierarquia habitacional na cidade do Rio de Janeiro, partindo de um estudo de caso no bairro Cidade Alta, local onde por vários anos realizei trabalho de campo, visando pesquisas na área da antropologia/sociologia urbana, e onde também vivenciei experiências de pertencimento ao lugar como morador.

Para início da conversa, preciso estabelecer quais são meus pressupostos ao falar de hierarquias habitacionais: elas não são somente hierarquias de locais, mas, também, das pessoas que neles habitam. ${ }^{2}$ O local em que se mora na cidade, na maior parte dos casos, pode representar a situação econômica, social e cultural dos

\footnotetext{
2 Segundo Bourdieu, a disposição dos agentes na cidade revela um espaço social inscrito e intimamente relacionado com o espaço físico: "a estrutura do espaço social se manifesta, assim, nos contextos mais diversos, sob a forma de oposições espaciais, o espaço habitado (ou apropriado) funcionando como uma espécie de simbolização espontânea do espaço social. Não há espaço, em uma sociedade hierarquizada, que não seja hierarquizado e que não exprima as hierarquias e as distâncias sociais, sob uma forma (mais ou menos) deformada e, sobretudo, dissimulada pelo efeito de naturalização que a inscrição durável das realidades sociais no mundo natural acarreta" (BOURDIEU, 2008, p. 160).
}

Cad. de Pesq. Interdisc. em Ci-s. Hum-s. Florianópolis, Santa Catarina, Brasil, ISSN 1984-8951

v.14, n.105, p.120-138, ago/dez 2013 
seus moradores, como também o seu espaço na sociedade. As favelas, por exemplo, percebidas por muitos como último patamar da hierarquia habitacional nas grandes cidades, costumam abrigar, na grande maioria essa representação sobre seus moradores, pessoas que ainda são excluídas da nossa sociedade e vistas preconceituosamente como "inferiores", como é o caso dos negros, dos pobres e das pessoas com pouco acesso a educação formal. ${ }^{3}$

Tanto é uma hierarquia de pessoas que muitos locais, antes estigmatizados, mudam de condição, desde que as pessoas que residam ali sejam removidas, e outras pessoas, que diferem das primeiras por sua posição econômica/cultural/social, passem a ocupá-los - processo denominado por Bourdieu de "trabalho de transplantação". 4 Assim, o estigma deixa de marcar o lugar e passa a acompanhar o grupo removido. O complexo Cidade Alta é exemplo real do processo relatado: essa área da cidade do Rio de Janeiro abriga ex-moradores de extintas favelas da Zona Sul - em especial, da Favela da Praia do Pinto - que trouxeram para onde foram removidos os estigmas em torno da "favela" e dos "favelados". A favela da Praia do Pinto se localizava no bairro do Leblon, onde hoje está o conjunto habitacional Selva de Pedra, que abriga uma população de classe média alta. O estigma da favela é hoje uma lembrança que só se faz presente por meio dos seus vizinhos da Cruzada São Sebastião ${ }^{5}$ e pelo apelido de "favelão", que é altamente rejeitado pelos mesmos moradores. ${ }^{6}$

\section{Rio de Janeiro e suas hierarquias habitacionais}

\footnotetext{
${ }^{3}$ Por mais que a favela seja um espaço heterogêneo, abrigando pessoas com diferentes faixas etárias, origens étnicas e formação escolar, o estigma imposto a esses espaços e seus moradores ainda identifica o espaço com os grupos mais marginalizados: "As pressões exercidas, em escala de classe ou do estabelecimento escolar ou em escala do conjunto habitacional pelos mais carentes ou os mais afastados das exigências constitutivas da existência 'normal' produzem um efeito de atração, para baixo, portanto de nivelamento, e não deixam outra saída que a fuga (na maioria das vezes interdita por falta de recursos) para outros lugares" (BOURDIEU, 2008, p. 166).

${ }^{4}$ Segundo Bourdieu o trabalho de transplantação, que faz profundas alterações no uso social de um espaço, acontece quando há "uma mudança das coisas e de um desenraizamento ou de uma deportação de pessoas, as quais suporiam transformações sociais extremamente difíceis e custosas" (BOURDIEU, 2008, p. 161).

${ }^{5}$ A Cruzada é um conjunto habitacional no Leblon que abriga ex-moradores da Favela da Praia do Pinto, removidos em meados da década de 50. Localiza-se vizinha a Selva de Pedra. Para maiores informações, confira Simões (2008).

6 "Chamar a Selva de Pedra de 'favelão', como algumas pessoas de fora o fazem, lembrando, dessa forma, a caracterização original do lugar é, para os atuais ocupantes, uma ofensa. É ter, em última análise, a mesma representação da Selva que seus moradores têm da Cruzada" (SANTOS; VOGEL, 1981, p. 120).
}

Cad. de Pesq. Interdisc. em Ci-s. Hum-s. Florianópolis, Santa Catarina, Brasil, ISSN 1984-8951

v.14, n.105, p.120-138, ago/dez 2013 
Se a hierarquia habitacional é também uma hierarquia de pessoas, percebemos que a primeira se origina na segunda. Desde o início da sua história, o Brasil teve hierarquias bem definidas: escravos e livres, entre os livres - nobres e não nobres; entre os não nobres - ricos, menos ricos, pobres, etc. As habitações, assim como hoje, obedeciam a essa lógica hierárquica. Exemplos clássicos de hierarquia habitacional na nossa história, que separavam grupos sociais, deram nome a duas grandes obras de Gilberto Freyre: Casa Grande \& Senzala (2004) e Sobrados \& Mocambos (2003).

A respeito da cidade do Rio de Janeiro, foi no final do século XIX que se começava a tomar como um problema público a hierarquia habitacional urbana, ${ }^{7}$ já que passavam a ser apontados como incômodos determinados tipos de habitação coletiva de baixa renda. Nesse período, misturavam-se, no centro da cidade, ricos e pobres, gozando de diferentes habitações. A grande massa de excluídos do desenvolvimento morava amontoada em cortiços no centro do Rio de Janeiro e em suas proximidades, tendo acesso total à vida da cidade que, naquela época, resumia-se praticamente a esse centro. ${ }^{8}$

Os cortiços, no final do século XIX, incomodavam de tal forma que sua presença passava a ser vista como um dos grandes empecilhos à modernização do centro da cidade, inspirada nos moldes europeus, e como um risco à saúde da população carioca em geral, pois eram percebidos como espaços propagadores de doenças e epidemias. Nesse momento, os discursos racistas, de modernização arquitetônica e da medicina higienista estavam em destaque no Brasil, todos embebidos por ideias evolucionistas (SCHUWARCZ, 1993). Os adeptos desses discursos eram todos contra, cada qual com seus argumentos, à existência dos cortiços e influenciaram as autoridades da época, provocando consequentemente uma progressiva extinção desse modo de habitação nas áreas nobres da cidade. Destruídos os cortiços, muitas pessoas ficaram sem ter onde morar.

\footnotetext{
${ }^{7}$ Procuro enfatizar aqui a hierarquia habitacional no que diz respeito aos tipos de habitação, por isso, não pretendo me aprofundar no que diz respeito à hierarquia que existe entre as regiões da cidade, apesar de apresentar informações de tal tipo no decorrer do texto.

8 "Apesar da precariedade, morar em cortiços tinha uma vantagem fundamental para os trabalhadores: ficar perto da oferta de trabalho" (Barbosa; Silva, 2005, p. 25).

Cad. de Pesq. Interdisc. em Ci-s. Hum-s. Florianópolis, Santa Catarina, Brasil, ISSN 1984-8951

v.14, n.105, p.120-138, ago/dez 2013
} 


\begin{abstract}
A crise habitacional era, todavia, completamente ignorada pelo poder estatal. Quando Pereira Passos, o prefeito 'bota-abaixo' que governou a capital federal entre 1902 e 1906 iniciou a sua reforma urbana, os cortiços e as casas de cômodos eram cada vez mais escassos e os morros pareciam ser a principal saída para uma população pobre que aumentava a cada dia (BARBOSA; SILVA, 2005, p. 26) ${ }^{9}$.
\end{abstract}

Destruídos os cortiços, as autoridades voltavam sua atenção para um novo modo de habitação nos morros, que posteriormente seria chamado de favela por causa de um dos seus primeiros e mais chamativos casos na cidade: o Morro da Favella (hoje, Morro da Providência). Esses morros abrigavam os novos pobres da cidade, como os expulsos dos cortiços e os ex-combatentes da guerra de Canudos. Esse novo ambiente habitacional passava a herdar todos os estigmas do cortiço e dos outros tipos de habitações populares consideradas inferiores.

A origem das representações negativas das favelas cariocas, segundo Valladares (2005), teve relação direta com a história de Canudos, que refletia outra hierarquia simbólica de lugares, opondo sistematicamente litoral e sertão. Uma das possíveis explicações da origem do nome "Morro da Favela" seria a semelhança deste com o "Morro da Favela", principal foco da resistência que existia em Canudos. A herança não seria só do nome, mas de todo um imaginário. ${ }^{10} \mathrm{O}$ livro Os sertões, de Euclides da Cunha (1975), era a obra mais lida no início do século, e as suas descrições negativas das formas de habitação e de vida que encontrou em Canudos povoaram o imaginário dos intelectuais brasileiros da época. Aqueles que procuravam pensar a favela tinham como referência tal obra, e a associação entre a favela e o povoado de Canudos era quase inevitável. Assim, os estigmas do sertão também passaram a recair sobre a favela.

Povoadas de lendas sempre interpretadas a partir de um viés rural, mitológico e negativo (como o sertão), as favelas cresciam, eram rejeitadas pela cidade e sempre percebidas como problemas a serem solucionados, como os cortiços foram um dia. A partir da década de 20 do século passado, teve início uma série de propostas que visavam livrar a cidade das favelas, incômodas diante de um projeto

\footnotetext{
${ }^{9}$ Marcante para a história dos cortiços foi à demolição em 1897, do "cabeça de porco" - o maior que existiu na cidade, deixando várias pessoas sem moradia.

${ }^{10}$ No Nordeste, no período da revolta de canudos, fazia-se uma oposição hierárquica entre o litoral e o sertão. O que era bom estava no litoral, o que estava no sertão, como a população de Canudos (que não aceitava a república e a modernização), deveria ser combatido em nome do progresso da Nação. Para maior aprofundamento no tema (cf. VALLADARES, 2005, p. 23-35).
} 
arquitetônico e estético que tinha como modelo as principais cidades europeias. Mas, as favelas cresciam e o estado não conseguia ter controle sobre tal fenômeno. Porém, conseguiu conter o avanço dessas habitações no centro, que passou a se dar nas regiões mais distantes e menos habitadas da cidade, hoje chamadas de zona norte e oeste.

Enquanto as favelas cresciam longe do centro, menores eram os problemas. Como analisaram Barbosa e Silva:

a favela era permitida, portanto, desde que obedecesse a uma condição fundamental: Ser invisível aos olhos burgueses ofuscados pelo glamour da arquitetura parisiense e pelo modo de vida moderno (BARBOSA; SILVA, 2005, p. 27).

Mas, as favelas não apareciam só nessas regiões da cidade. A zona sul, área escolhida para abrigar as classes economicamente mais favorecidas e os bens raros da cidade, também via nascer tais habitações em seu território. Uma dessas seria a famosa favela da Praia do Pinto. Localizada no Leblon, próxima à praia, era identificada pela elite como uma "mancha" dentro daquela área residencial em expansão. Foram então construídos, na década de 60, conjuntos habitacionais na zona norte e na zona oeste que tinham dois objetivos: um não divulgado, que era liberar os terrenos da zona sul para construções imobiliárias direcionadas às classes média e alta; e o outro, bem divulgado (inspirado nas ideias higienistas), era acabar com as favelas e "favelados", tirando estes últimos dos barracos e mandando-os para prédios com luz, água encanada, etc. Acreditava-se aqui na "civilização" do favelado (transformando-os em "corpos dóceis"11) e operava-se o seu distanciamento físico-espacial das classes média e alta.

Muitos se mudaram para esses conjuntos contra a sua vontade. Sair da favela da Praia do Pinto era perder o acesso fácil à praia e a proximidade do emprego e outras oportunidades de gerar renda, e ainda perder a sua casa para ter que pagar

\footnotetext{
11 Segundo Foucault (2008), por meio da disciplina e do controle os corpos podem se tornar submissos, corpos dóceis, tendo as suas capacidades (em termos econômicos de utilidade) aumentadas. Quando o indivíduo não é percebido como um grande inimigo, ele pode ser disciplinado, e além de estar sob controle ainda pode tornar-se útil para a sociedade - é o "fazer viver, deixar morrer" (FOUCAULT, 2005), que com o desenvolvimento de toda uma ciência (como a medicina) visa aumentar a capacidade da vida em vez de exterminá-la. Essa biopolítica se realiza a partir de uma série de dispositivos de disciplina e de controle, presente em muitas instituições e práticas que adotaram uma postura panóptica de ação (FOUCAULT, 2008). Entre essas instituições, Foucault identifica fábricas, escolas, conventos, entre outros. As pessoas "internadas" nesses lugares constituiriam corpos dóceis, já que estão sendo constantemente regulados por dispositivos disciplinares, e por conta disso não ofereceriam perigo à sociedade. As remoções para os conjuntos habitacionais se apresentavam como um processo de civilização, tornando o "favelado" mais um morador na cidade, sendo dócil e obediente a sua lógica.
}

Cad. de Pesq. Interdisc. em Ci-s. Hum-s. Florianópolis, Santa Catarina, Brasil, ISSN 1984-8951 v.14, n.105, p.120-138, ago/dez 2013 
outra em um lugar onde nem podia escolher - afinal, na zona sul, esse morador não pagava conta alguma. Somente um grande incêndio sem proporções, que destruísse todas as habitações, seria capaz de obrigar todos os moradores a aceitarem a mudança de bairro.

Conjuntos habitacionais como Cidade Alta e Cidade de Deus acolheram os removidos dessas localidades. Criava-se na hierarquia habitacional da cidade uma nova modalidade: algo que se encontra entre o conjunto habitacional e a favela, ora usando uma identidade, ora usando outra. Um termo cunhado pelo governo municipal na década de 90 chama esses locais de "áreas favelizadas". ${ }^{12}$ Certamente, esse nome não dá conta da complexidade identitária de tais locais, mas reconhece, por meio da estigmatização desses espaços, que os planos "civilizatórios" dos governos da década de 60/70 efetivamente não vingaram. Extermina-se um espaço (favela), mas não a sua cultura e nem os seus estigmas: esses foram removidos junto com os seus moradores como se estivessem inscritos em seus corpos.

É preciso lembrar também que essas diferentes hierarquias se desdobram em muitas outras. Dá mais status morar numa favela da zona sul do que na Cidade de Deus ou Cidade Alta, por exemplo. O estudo de caso que apresento tem a intenção de mostrar as questões da hierarquia habitacional no bairro Cidade Alta, que está longe de ter uma identidade habitacional uniforme, mas, em vez disso, possui uma série de pequenas hierarquias distintivas e lógicas classificatórias que se mostram de alto interesse para a reflexão socioantropológica.

\section{Cidade Alta: descrição e hierarquias}

A Cidade Alta é um sub-bairro dentro do grande bairro de Cordovil, fazendo divisa com o bairro de Parada de Lucas, na zona norte do Rio de Janeiro, próximo à Baixada Fluminense. Formado por três conjuntos habitacionais e três favelas, esse espaço da cidade deve abrigar uma média de quarenta mil moradores. A origem da Cidade Alta se dá no ano de 1969, com a construção do seu primeiro e principal

\footnotetext{
${ }^{12}$ Em 1998 o programa Pró-Morar da Prefeitura do Rio de Janeiro classificou o conjunto Cidade Alta como "área favelizada". Os critérios usados para tal classificação foram: pouca iluminação, presença forte e naturalizada do tráfico e a má conservação dos prédios e apartamentos (NASCIMENTO, 2003, p. 81).
}

Cad. de Pesq. Interdisc. em Ci-s. Hum-s. Florianópolis, Santa Catarina, Brasil, ISSN 1984-8951

v.14, n.105, p.120-138, ago/dez 2013 
conjunto habitacional: o conjunto Cidade Alta. Logo após, a localidade ganhou outros dois conjuntos habitacionais e duas favelas. Para o conjunto Cidade Alta vieram principalmente ex-moradores de comunidades populares na zona sul do Rio de Janeiro: o parque proletário da Gávea e a Favela da Praia do Pinto (Leblon). ${ }^{13}$

O conjunto Cidade Alta é o principal desse sub-bairro. Entre o conjunto Cidade Alta e o conjunto Porto Velho, fica o Conjunto Vista Mar ou o Bancários, como é chamado pelos moradores. De todas as unidades desse bairro, é a que abriga os prédios considerados "mais organizados"14 e a única onde a taxa de condomínio é obrigatória (por volta de 150 reais), tendo seus moradores direito a benefícios como garagem e funcionários à disposição dos prédios. O conjunto Porto Velho, mais conhecido como "Pé Sujo" tem uma realidade parecida com a Cidade Alta porém menos estigmatizada. Pelo fato de o tráfico de drogas e a violência acontecerem de forma mais forte e transparente "lá em cima" (referem-se ao conjunto Cidade Alta, que fica na parte mais alta do bairro) e por experimentar menos alterações no espaço físico, o morador desse conjunto se sente privilegiado em relação aos do conjunto Cidade Alta.

Três favelas fazem parte do bairro: Parque Proletário de Cordovil (conhecida como Divinéia), Avilã e Cambuci. A Cambuci é uma favela que atravessa toda a Cidade Alta, cortando todos os conjuntos, sendo paralela à Rua Água Doce, a principal do complexo. A favela da Divinéia se localiza ao fundo da igreja católica e de alguns prédios. Estes estariam atrás do "topo" (parte mais alta) da Cidade Alta, já que a Igreja está no final da Rua Água Doce. A favela da Avilã se localiza atrás de uma parte da Cambuci. Vale lembrar que essas favelas foram formadas por exmoradores do conjunto que venderam os apartamentos para ficar com o dinheiro e

\footnotetext{
${ }^{13}$ A mudança para a Cidade Alta tratou-se de uma grande empreitada. Em números, a mudança dos moradores da praia do Pinto para a Cidade Alta representou 732 viagens de caminhão e 1464 viagens de Kombi. Essa empreitada reuniu uma média de 5920 trabalhadores para transportar 2928 famílias, que chegavam a uma média de 16.600 pessoas (GOVERNO DO ESTADO DA GUANABARA, 1969, p. 84).

${ }^{14}$ Como "mais organizados", segundo os informantes consultados para essa pesquisa, podem ser identificados aqueles prédios e espaços do bairro que menos receberam alterações em relação ao projeto original. Essa representação coincide com a da "boa forma urbana", que, segundo Mello e Vogel (1983), parte de uma lógica racionalista-modernista (de cunho positivista), praticada por muitos arquitetos e urbanistas, que conduz a ordenação dos espaços segundo ditames que muitas vezes não dialogam (e até desconsideram) com as práticas sociais relacionadas ao uso da moradia por parte dos grupos populares. Os edifícios dos conjuntos habitacionais da Cidade Alta, assim como muitos outros construídos pela cidade nas décadas de 60 e 70, obedeceram essa lógica da "boa forma urbana".
}

Cad. de Pesq. Interdisc. em Ci-s. Hum-s. Florianópolis, Santa Catarina, Brasil, ISSN 1984-8951 v.14, n.105, p.120-138, ago/dez 2013 
invadiram terrenos baldios, construindo casas. A maioria das pessoas que formou essas favelas já experimentou antes a vida em favela na praia do Pinto.

Segundo Nascimento (2003), a Cidade Alta se caracteriza por ser um complexo habitacional que traz em si as características de uma favela (principalmente o conjunto Cidade Alta), quer seja no modo de ser de seus habitantes, quer seja no modo de adquirir e de transformar o espaço. Hoje, a Cidade Alta, juntamente com a Cidade de Deus, tornou-se um dos principais complexos habitacionais que são vistos como favelas, representação essa compartilhada pelo Estado, pelos outros moradores da cidade e pelos seus próprios moradores. Sendo assim, é comum encontrar na boca dos moradores a afirmação de que é a Cidade Alta uma "favela de cimento armado". Uma informante de Nascimento, certamente referindo-se aos trágicos episódios da Praia do Pinto, conseguiu definir bem o que aconteceu na Cidade Alta: "tiraram o povo da favela, mas não tiraram a favela do povo"(NASCIMENTO, 2003, p. 4).

Para as pessoas de fora e para o Estado, ser morador desse bairro é morar em uma "área favelizada" ou "favela vertical". É encontrar-se coletivamente em uma das mais baixas posições da hierarquia habitacional da cidade, perdendo só para as favelas propriamente ditas. Para os moradores, tais classificações não se dão de forma tão simples. Morar no bairro não iguala os seus moradores, é preciso saber em qual conjunto habitacional este mora (ou se mora em uma das três favelas). Sua posição de moradia no complexo poderá dizer muito da pessoa: sua condição financeira, sua origem e seu status no bairro, e até mesmo sua moralidade, seus valores, seus tabus e suas permissividades.

A primeira e mais básica das hierarquias é a seguinte: é melhor morar em um dos três conjuntos habitacionais do que nas favelas do complexo. Estes, mesmo com as suas diferenças, possuem, para os moradores dos conjuntos, uma indiscutível organização (representação baseada na lógica racionalista-modernista de ordenação do espaço) maior que a das favelas. Nessas favelas, as casas foram, na sua grande maioria, adquiridas por posse, e as contas como luz e água não são pagas (são os "gatos"). Nos conjuntos habitacionais (em especial, Cidade Alta e Pé Sujo) existem muitos moradores que fazem "gatos", não colaboram com a organização dos prédios e do conjunto e não chegam a pagar todas as prestações 
do apartamento, mas se colocam em condições superiores às dos moradores das favelas do bairro do ponto de vista de uma escala hierárquica habitacional.

Porém, quero observar de forma mais específica a distinção que se estabelece entre os três conjuntos habitacionais: Cidade Alta, Bancários e Pé Sujo. Mesmo que todos formem a grande Cidade Alta, posso dizer (não só como pesquisador, mas também como ex-morador do local) que esses conjuntos possuem grandes diferenças que acabam por constituir hierarquias sociais. Isso fica visível quando um morador se muda de um conjunto para o outro: tal processo poderá ser classificado como ascensão ou declínio social, dependendo de onde veio e para onde vai. Entrevistei seis moradores que migraram de um conjunto para o outro e uma ex-moradora que se mudou do bairro há alguns anos. Essas entrevistas deixaram claras algumas informações sobre as diferentes escalas na hierarquização habitacional existente na Cidade Alta.

Primeiramente, desejo apresentar os meus entrevistados e as suas respectivas mudanças: Fabiane - Pé sujo/Cidade Alta; Bruno - Pé sujo/Cidade Alta; Bianca - Bancários/Cidade Alta; Fernando - Pé sujo/Bancários; Oberdan - Cidade Alta/Pé sujo; Márcia - Cidade Alta/Bancários; e Alessandra - Cidade Alta/ Outro bairro. ${ }^{15}$ Dessas pessoas entrevistadas, temos assim: três que moram no principal conjunto (Cidade Alta); três que ainda moram no bairro e que já foram moradores do conjunto citado; e uma pessoa que não mora mais no bairro.

Algumas perguntas feitas revelaram uma clara correspondência no quadro de representações dessas pessoas sobre algumas questões. Duas constituíram-se como uma verdadeira unanimidade. Em uma dessas perguntas, pedia aos entrevistados que colocassem em uma ordem, de melhor para pior, os três conjuntos habitacionais, e assim foram todas as respostas: em primeiro, o Bancários; em segundo o Pé Sujo; e em terceiro lugar o Cidade Alta. Outra pergunta que se revelou assim foi: "você considera a sua mudança um declínio, um progresso ou acredita que ficou na mesma?". Todos que hoje moram na Cidade Alta responderam que sofreram um processo de declínio social, os outros responderam que foi um progresso. Tais perguntas ajudaram a constatar o que já observava e

\footnotetext{
${ }^{15}$ Não foi encontrado nenhum caso de morador que tenha migrado do Bancários para o Pé sujo. Assim, esse exemplo estará ausente nesse relato.

Cad. de Pesq. Interdisc. em Ci-s. Hum-s. Florianópolis, Santa Catarina, Brasil, ISSN 1984-8951

v.14, n.105, p.120-138, ago/dez 2013
} 
experimentava como "nativo": há uma superioridade hierárquica do conjunto Bancários sobre os outros dois, e do conjunto Pé Sujo sobre o Cidade Alta.

O motivo principal que provocou a mudança para o conjunto Cidade Alta foi a falta de recursos financeiros: os três entrevistados (Bruno, Bianca e Fabiane) mudaram-se após o casamento, pois não queriam permanecer na casa dos pais, mas não tinham recursos para continuar no seu conjunto de origem. Fabiane, por exemplo, conseguiu comprar um apartamento de dois quartos por doze mil reais na Cidade Alta. Um apartamento de igual proporção custava (no mesmo período, em 2005) no Pé Sujo a partir de vinte e cinco mil, e no Bancários a partir de trinta mil reais. Todos esperam futuramente poder mudar de onde estão, ou para um dos outros dois conjuntos ou para fora do bairro. Isso se deve ao fato de que esses "migrantes" não se sentem incorporados ao Cidade Alta. A fala de Fabiane transparece tal informação: "moro aqui há alguns anos e não consigo me sentir parte deste lugar".

Os que mudaram do Cidade Alta para os outros dois conjuntos ou para outro bairro alegaram diversos motivos para tal ação, mas estes podem ser reunidos em três: (1) falta de "organização" do conjunto, causada principalmente pela inexistência de uma administração oficial dos prédios, de manutenção e limpeza e pela existência de construções irregulares; (2) medo da violência, atribuída em grande parte ao crime organizado no tráfico de drogas; e (3) uma melhora da situação financeira, o que possibilitou e motivou a mudança. Essas mesmas situações também foram apontadas pelos que migraram para o Cidade Alta como os motivos que os fizeram considerar a mudança para o conjunto como um declínio social.

Outra pergunta que ajudou a revelar o que os entrevistados pensam sobre o principal conjunto do complexo foi: "você acha que a Cidade Alta é uma favela?". Dos sete entrevistados, dois afirmaram que sim, outros três afirmaram que sim, mas fizeram questão de ressaltar que era uma "favela de cimento armado" (hierarquicamente superior à favela de tábua e à favela de alvenaria) e ainda dois afirmaram que não era favela. Essas duas últimas respostas, porém, não divergiram muito das outras, pois um afirmou que "não é favela, mas tem desorganização acentuada como favela e é submetida às normas de favela, se aproximando de uma favela" (Fernando) e o outro afirmou que "a Cidade Alta não é favela, seus moradores que são favelados" (Oberdan). 
Perguntei ainda se os outros conjuntos do bairro também poderiam ser considerados favelas. A maioria das respostas girou em torno do processo: "estão virando", ou responderam que sim, mas numa escala muito inferior à do Cidade Alta. Uma minoria respondeu que não.

A última das perguntas: "o que é favela na sua opinião?". Essa pergunta pegou a todos de surpresa. Houve uma preocupação dos entrevistados em não dar uma resposta "clichê" ou preconceituosa. As respostas reunidas elegeram as seguintes características como essenciais em uma favela: lugar onde as leis e as regras não funcionam, presença forte da violência e da criminalidade, onde as pessoas têm pouca educação e cultura, uso do som alto, falta de respeito com o vizinho, pobreza, desorganização social, lugar não habitável, becos e construções irregulares. Geralmente, as respostas eram iguais aos motivos apontados como defeitos do conjunto Cidade Alta. A associação deste conjunto com as representações que tinham da favela era inevitável.

Como disse, a "desorganização" do conjunto habitacional foi vista como um dos principais motivos que fazem do Cidade Alta a "favela de cimento armado". Essa desorganização se traduz principalmente na estrutura administrativa dos prédios e nas construções consideradas "irregulares", que são as chamadas "puxadas", as quais ampliam o apartamento utilizando o espaço público do prédio ou da própria calçada da rua. Quanto à administração dos conjuntos, somente o Bancários possui uma administração oficial de estrutura condominial, terceirizada por uma empresa que cobra a taxa do condomínio, contrata os funcionários, cuida da conservação dos prédios e fiscaliza o cumprimento de regras previstas na convenção, como a proibição das construções irregulares e "gatos" (mas, nem sempre tão eficiente). Todas essas características fazem do Bancários, segundo o entrevistado Bruno, "o presuntinho do pão" neste complexo habitacional.

Há alguns anos atrás, pude presenciar um episódio que me permitiu perceber como é diferente o ethos dos moradores do Bancários para o do Cidade Alta. Fui morador do Bancários e há uns três anos encontrei uma senhora conhecida, moradora do Cidade Alta, que me anunciou com alegria a mudança para o meu prédio. Era mais uma moradora do local realizando um sonho: mudar para o Bancários, um rito de passagem que representa uma ascensão social, como já apontei. O apartamento, que se localiza no segundo andar, estava em obras para a 
mudança dessa senhora e sua família. Pensei inclusive em convidá-la para ser uma das minhas entrevistadas. Quando fui procurá-la, soube por vizinhos que esta senhora não iria mais morar no prédio. Os motivos que contribuíram para sua frustração foram: a descoberta de um condomínio obrigatório e não espontâneo (como é no Cidade Alta) de quase cento e cinquenta reais cujo não pagamento pode provocar expulsões para os devedores; a proibição imediata que recebeu para a construção de uma "puxada" que estava começando a fazer em seu futuro apartamento; e a rejeição dos moradores do prédio a alguém que estaria vindo para "desorganizar" o ambiente. Diante dessas pressões, a senhora desistiu da compra do apartamento.

Tanto no Pé Sujo, quanto no Cidade Alta, não há uma empresa responsável pela administração do conjunto. Na maioria dos edifícios, elege-se informalmente um síndico e esse fica responsável por recolher uma taxa (que chamam de condomínio) e aplicá-la na limpeza e melhoria do prédio. Funciona assim também no Cidade Alta, mas com uma diferença: a não-oficialidade dessa taxa faz com que a maioria dos moradores dos prédios não pague e que, em alguns deles, sequer exista esse processo de recolhimento de dinheiro ou qualquer outra forma de associação pela conservação do prédio. No Pé Sujo, no entanto, a informalidade ganha um caráter formal, fazendo com que o morador não-pagante sofra constrangimentos públicos e sanções sociais que acabam pressionando o mesmo a ser fiel ao pagamento. $\mathrm{Na}$ entrada dos prédios, há geralmente uma tabela, feita pelo síndico, que permite visualizar quem paga ou não com regularidade o condomínio. As fofocas e críticas que decorrem dos dados dessa tabela fazem com que o morador pense duas vezes antes de atrasar o seu pagamento. Há, no Pé Sujo, pouquíssimas "puxadas". Essas não são bem aceitas por seus moradores, pois podem provocar comparações com o Cidade Alta. Tal rejeição faz com que os moradores não se aventurem em construílas. Essa rejeição nasce do fato de que, diferentemente dos moradores do Cidade Alta, são poucos os moradores do Pé Sujo que são ex-moradores de favela. Por isso, rejeitam tanto esse rótulo quanto essa associação.

Falando nas "puxadas", todos os entrevistados rejeitaram esse tipo de construção, apontando-o como um dos principais culpados pela "favelização" e "desorganização" do conjunto. As "puxadas" são rejeitadas por moradores e exmoradores, jovens e velhos. Mas afinal, o que são as "puxadas"? O termo puxada 
(ou puxadinho) é uma categoria nativa que se refere às construções feitas para aumentar a casa ou apartamento por populações de baixa renda, criando um ou mais cômodos em favor de uma necessidade ou do conforto de seus moradores. São geralmente construções projetadas pela família e colocadas em prática por pedreiros, sem qualquer supervisão ou coordenação de profissionais de arquitetura ou engenharia. É uma prática comum e cada vez mais disseminada no Cidade Alta desde o final da década de 80. Vale lembrar que esse tipo de construção para aumentar o imóvel não é algo exclusivo desse conjunto habitacional: é um fenômeno presente em quase todas as favelas. Geralmente, nas favelas, as casas são construídas horizontalmente e aumentadas verticalmente, tendo a laje como base da nova construção. A laje pode dar espaço a um novo cômodo, a uma nova casa, a um espaço de lazer da família e até a um novo local público (Igreja, escola, comércio, etc., com as casas deslocadas para o andar de cima). Esse esquema de crescimento pela laje é aceito socialmente nas favelas e praticado pela grande maioria dos seus moradores. No conjunto Cidade Alta, essa prática também faz parte do seu cotidiano, mas, como o Cidade Alta é um conjunto habitacional de edifícios, já é vertical. Sendo assim, seu crescimento se dá de forma horizontal, e o papel da laje nas favelas é ocupado pela parede que dá para rua, ou pela sua ausência, quando a mesma é derrubada. A casa se estende no espaço da rua, com o novo cômodo ocupando o que, antigamente, era uma área comum do prédio ou um pedaço da calçada.

Mas a aceitação das "puxadas" no Cidade Alta parece ser diferente, quando comparada às outras favelas e demais espaços populares da cidade. Conforme meus dados etnográficos apontam (tanto pelos relatos, como pela observação das práticas), tal prática não é aceita por vários moradores, apesar de muitos deles realizarem esse tipo de construção: classificam-nas como uma das principais culpadas pela "favelização" e "desorganização" do conjunto. Elas são rejeitadas por moradores e ex-moradores, novos e antigos, mas isso não significa que os mesmos que as rejeitam não cogitem a possibilidade de construir uma. "Vê a minha puxada, é coisa de bacana. Não é igual a essas 'coisas' que você vê por aí!" - disse um 
informante certa vez no campo para justificar a sua rejeição à prática e, ao mesmo tempo, o uso que fez dela. ${ }^{16}$

Sendo assim, por que essa prática tão disseminada não é aceita por boa parte dos moradores do Cidade Alta? Primeiramente, segundo o discurso dos mesmos moradores, por tornar o conjunto parecido com favelas, no que diz respeito as "construções desorganizadas", que fazem os edifícios perderem o padrão homogêneo inicial (identificado com uma "boa forma urbana" - MELLO; VOGEL, 1983). Depois, uma possível leitura, seria porque tais construções misturam espaços que refletem universos diferenciados de valores na nossa sociedade: a casa e a rua.

Segundo DaMatta (1997a), casa e rua são, na sociedade brasileira, esferas opostas que sustentam valores diferentes, que são praticados pelas mesmas pessoas. Como entender esses comportamentos diferentes? DaMatta explica:

\begin{abstract}
Sustento pois que essa observação não é uma mera questão de mudança de contexto, isto é, do fato plenamente conhecido e trivial de que todo ser humano muda de opinião dependendo das circunstâncias. Não é desse fato universal que estou falando. Sei que ele também ocorre entre nós. Mas, estou me referindo a espaços, a esferas de significação social - casa, rua e outro mundo - que fazem mais do que separar contextos e configurar atitudes. É que eles contém visões de mundo e éticas particulares. Não se trata de cenários ou de máscaras que um sujeito usa ou desusa - como nos livros de Goffman - de acordo com as suas estratégias diante da 'realidade', mas de esferas de sentido que constituem a própria realidade e que permitem normalizar e moralizar o comportamento por meio de perspectivas próprias (DAMATTA, 1997a, p. 47).
\end{abstract}

O crescimento horizontal do Cidade Alta faz com que um espaço público, que é a calçada ou a rua, se torne extensão da casa, criando uma fusão entre esses dois espaços, a princípio, opostos. Tal processo, segundo DaMatta (1997a, p. 54), não poderia se dar de qualquer forma, pois "não posso transformar a casa na rua e nem a rua na casa impunemente". Essas construções no conjunto Cidade Alta, a princípio, desobedecem as regras oficialmente instituídas, como a proibição de se invadir o espaço público para uso privado. Apoiando-me nessa teoria de DaMatta (1997a), é possível pensar que os moradores do Cidade Alta, mesmo que inconscientemente, rejeitam a fusão de espaços tão diferentes para que essa sagrada hierarquia não seja quebrada e desrespeitada de modo leviano. Procura-se

\footnotetext{
${ }^{16}$ É preciso ressaltar que os moradores que ainda não fizeram "puxadas" podem ser classificados em dois: aqueles que são contra esse tipo de prática e aqueles que não tiveram oportunidade. Fazem uma "puxada" com facilidade aqueles que moram no primeiro andar, já os moradores dos andares superiores, muitas vezes, dependem do seu vizinho de baixo construir uma para poder fazer a sua.
}

Cad. de Pesq. Interdisc. em Ci-s. Hum-s. Florianópolis, Santa Catarina, Brasil, ISSN 1984-8951

v.14, n.105, p.120-138, ago/dez 2013 
preservar a casa dos valores da rua e vice-versa. No entanto, no Brasil, há múltiplas possibilidades ambíguas entre os dois opostos.

Por fim, mas sem esgotar as muitas e complexas relações hierárquicas existentes no complexo habitacional Cidade Alta, quero destacar outra hierarquia muito interessante: os moradores do conjunto Cidade Alta se classificam entre "favelados" e "não favelados". Em algumas ocasiões, o morador pode se identificar como favelado para receber benefícios como a caridade de um patrão ou uma ajuda governamental, mas, em grande parte do tempo, o favelado é sempre o "outro".

Existem critérios para se identificar um morador como favelado ou não. Geralmente são: falta de educação (no sentido de comportamento); não cultivo da limpeza do seu prédio; falta de conhecimento; e alterações irregulares do espaço (como as "puxadas" ou construção de trailers nas ruas). Porém, todas essas noções podem ser relativizadas por meio da criação de novas formas de hierarquia, que acabam acionando novos estereótipos e fazendo do "outro" o favelado, mesmo que o sujeito da acusação tenha ou pratique alguma das atitudes relacionadas acima. Como exemplo, gostaria de citar os moradores que fazem "puxadas" e acabam falando que não são favelados, pois fizeram uma "puxada bem feita", enquanto muitos a fazem "de qualquer jeito". Essa mútua estigmatização é ativada em um contexto onde o morador procura desfiliar-se da imagem do favelado e dos seus estigmas e, em função disso, aponta para outros moradores, responsabilizando-os pela frustração do projeto arquitetônico e social inicialmente previsto: o de transformar favelados em moradores de conjunto habitacional.

\section{Conclusão}

Dumont, em seus escritos sobre hierarquia, provavelmente não pensou na sociedade brasileira como um exemplo, mas suas teorias sobre igualdade e hierarquia podem ser muitos úteis para o entendimento da nossa realidade. Para esse pensador

\footnotetext{
o princípio igualitário e o princípio hierárquico são realidades primeiras, e das mais cerceadoras, da vida política ou da vida social em geral. Pode-se ampliar aqui a questão do lugar da ideologia na vida social: metodologicamente, tudo o que se segue, no plano geral e nos detalhes, responderá a essa questão (DUMONT, 2000, p. 51).
} 
No Brasil, onde a hierarquia e igualdade se encontram simultaneamente presentes, como apresenta DaMatta (1997b, p. 169-259), ambas influenciam os nossos contextos sociais. Por mais que as hierarquias existam, o que predomina como discurso oficial é o da igualdade, e por muitas vezes este manifesta sua influência e poder. Os moradores do complexo Cidade Alta, por exemplo, em muitos momentos se sentem iguais, como humanos, brasileiros, cariocas, suburbanos, pobres. Usam espaços comuns, como comércios, igrejas, mercados, etc. Também os interesses coletivos, muitas vezes, despertam o discurso igualitário, sem necessariamente suspender o discurso hierárquico, e o uso da hierarquia nem sempre tem o objetivo de estigmatizar o outro, mas, sim, de defender-se do estigma, mostrando no outro o "endereço" da acusação.

Portanto, o resultado dessa pesquisa atesta que muitas outras coisas podem ser pensadas, no que diz respeito a temas tão essenciais para a sociedade brasileira como são a hierarquia e a igualdade. Em especial, o Cidade Alta e as suas complexas relações sociais se revelam como um rico campo para esse tipo de análise extensiva a tantos outros bairros e regiões morais na cidade. 


\section{Referências}

BARBOSA, J. L.; SILVA, J. de S. e. Favela: Alegria e Dor na cidade. Rio de Janeiro: Editora Senac Rio, 2005.

BOURDIEU, P. Os efeitos de lugar. In: BOURDIEU, P. A miséria do mundo. Petrópolis: Vozes, 2008.

CUNHA, E. da. Os sertões. São Paulo: Editora Círculo do livro S.A., 1975.

DAMATTA, R. Carnavais, malandros e heróis: Para uma sociologia do dilema brasileiro. Rio de Janeiro: Rocco, 1997a.

DAMATTA, R. A Casa \& A Rua: Espaço, cidadania, mulher e morte no Brasil. Rio de Janeiro: Rocco, 1997b.

DUMONT, L. Homo hierarchicus: O sistema das castas e suas implicações. São Paulo: Edusp, 2000.

FOUCAULT, M. Em defesa da sociedade. São Paulo: Martins Fontes, 2005.

FOUCAULT, M. Vigiar e punir: História da violência nas prisões. Petrópolis: Vozes, 2008.

FREYRE, G. Casa-grande \& senzala. São Paulo: Global, 2004.

FREYRE, G. Sobrados \& mocambos. São Paulo: Global, 2003.

GOVERNO DO ESTADO DA GUANABARA. Rio operação favela. Rio de Janeiro, 1969.

MELLO, M. A. da S.; VOGEL, A. Lições da rua: O que um racionalista pode aprender no Catumbi. Arquitetura revista, Rio de Janeiro, v.1, n.1, p. 67-79. 1983.

NASCIMENTO, D. N. do. Favela de cimento armado: um estudo de caso sobre a organização comunitária de um conjunto habitacional. 2003. 133 f. Dissertação 
(Mestrado em Ciências Sociais) - Universidade do Estado do Rio de Janeiro, Rio de Janeiro, 2003.

SANTOS, C. N. F. Dos; VOGEL, A. Quando a rua vira casa: A apropriação de espaços de uso coletivo em um centro de bairro. Rio de Janeiro: IBAM/NUFEP, 1981.

SCHWARCZ, L. M. O espetáculo das raças: Cientistas, instituições e questão racial no Brasil 1870-1930. São Paulo: Companhia das letras, 1993.

VALLADARES, L. do P. A invenção da favela: Do mito de origem a favela.com. Rio de Janeiro: Editora FGV, 2005.

Artigo:

Recebido em: 01/06/2012

Aceito em: 23/11/2013 